\title{
Representing whose access and allocation interests? Stakeholder perceptions and interests representation in climate governance
}

\author{
Timothy Cadman ${ }^{1}$, Tek Maraseni ${ }^{2}$, Hugh Breakey ${ }^{3}$, Hwan Ok Ma
}

\author{
${ }^{1}$ Griffith University, t.cadman@griffith.edu.au, 170 Kessels Rd, Nathan 4111 Queensland, Australia \\ ${ }^{2}$ University of Southern Queensland, Toowoomba, Queensland, Australia \\ ${ }^{3}$ Griffith University, Nathan Queensland, Australia \\ ${ }^{4}$ International Tropical Timber Organisation, Yokohama, Japan
}

\section{Introduction}

Given the distance from power for some stakeholders, ensuring that relevant interests are represented in global venues is a considerable governance challenge (Stiglitz, 2003, p. 61). Stakeholder inclusion, or 'inclusiveness', is a critical aspect of interest representation at the global level, and varies greatly depending on the institutional context in question (KoenigArchibugi, 2006, p. 13). There has been recognition for some time that globalization, and the post-modern experiences of complex governance it has brought about, requires a reconfiguration of interest representation in contemporary public administration (Rhodes, 1997, p. 198). In the supra-national polity of the EU, for example, inclusiveness has been identified as a fundamental principle of 'good' governance and legitimacy (Schmidt, 2013, pp. 2-3; Smismans, 2004, p. 26).

Governance scholars have broken down inclusiveness into two concepts: weight and access. 'Weight', which may be linked to the notion of equality, implies the degree of influence that participants are able to exert in a given policy context: the more balanced the power, the greater the equality between participants. 'Access' denotes the range of stakeholders, and the amount of influence they may exert in policy content-development. Governance systems can therefore be determined to be inclusive when stakeholders are not only involved in decision- 
making, but their input is both formally and informally acknowledged in actual policy (Koenig-Archibugi, 2006, pp. 14-15). It is argued that interest representation is most inclusive when previously excluded, or marginalized voices and perspectives, are actively encouraged (Young, 2000, p. 8). This work on governance dovetails with the recent 'procedural turn' in the literature on climate justice. This new area of ethical focus eschews commentary on the equitable distribution of mitigation/adaptation costs and benefits, instead exploring fair terms for international discourse and the procedural justice required by 'public reason', whereby nations develop through norms, principles and policies through fair terms of deliberation (Boran, 2016; Boran \& Katz, 2017; Breakey, 2015).

Seeking the involvement of such interests has little meaning if the resources for their participation are not available. Traditionally, it is only the most well-resourced organisations that have the capacity to attend and be involved in global policy deliberations. This limitation may be mitigated if there are compensating opportunities from groups to collaborate. In this regard, the growth of network-models of governance has been seen as providing a degree of compensation for those groups that cannot attend global (international) venues of powersuch as the UNFCCC Conference of Parties (COP). This is, of course, contingent on the resourcing of those networks through which the absent interests are represented (Scholte, 2004, pp. 223-225).

Scholars identify a wide range of resources required for effective interest representation. Clearly, economic resources are required (for such basic necessities as travel, food and accommodation). Technical capacity (including know-how, experience and expertise) is also important, as is institutional support (Mason, 1999, pp. 72-73). These have all been identified as structural framework conditions for the development of good (effective) environmental policy for quite some time (Janicke, 1992; Jänicke, 1996). Beyond the need for economic, technical and institutional capacity-building, there is also a need for the appropriate distribution of the monetary and non-monetary benefits created by the implementation of those policies in order for governance systems to function effectively. These factors are pronounced during policy formulation, such as has been observed in the policy arena of emissions reduction activities such as REDD+. Finally, benefit sharing throws up its own governance challenges, particularly in terms of who receives those benefits (Chapman, Wilder, \& Millar, 2014, p. 271). 
While international climate initiatives can be seen to be inclusive of various stakeholder interests, the allocation of resources to facilitate their active participation continues to be problematic. Previous studies suggesting the existence of a 'South/North' divide in global climate governance appear to be confirmed, although this observation is qualified. These findings have implications for the future implementation of activities aimed at reducing global greenhouse gas emissions under the 2015 Paris Agreement, and for any new market mechanisms that eventuate, notably the so-called 'sustainable development mechanism' (SDM).

This chapter presents a synthesis of findings from quantitative and qualitative investigations of the perspectives of participants involved in international climate governance, conducted over the period 2010-2015. In this study, an established framework of principles, criteria and indicators (PC\&I) for institutional governance was applied to two mechanisms under the United Nations Framework Convention on Climate Change (UNFCCC): the initiative referred to as 'Reducing emissions from deforestation and forest degradation and the role of conservation, sustainable management of forests, and enhancement of forest stocks in developing countries' (REDD+); and the Clean Development Mechanism (CDM) of the Kyoto Protocol (KP). Assessment focuses on the governance value of interest representation in terms of inclusiveness (access) and resources (allocation). It begins by outlining the historical context of UNFCCC, as well as CDM and REDD+, and continues with a delineation of the methods adopted, and results to reveal a relatively consistent set of results across the elements investigated, with inclusiveness receiving the highest score of all the governance indicators, and resources the lowest. The CDM was the weakest performer.

\section{Challenges confronting climate governance}

A range of academics and commentators has pointed to governance problems with the programmes and mechanisms of international climate governance (Cadman, 2013; Forsyth, 2009; Hoffmann, 2011; Knieling \& Leal Filho, 2012; Lederer, 2011; Lyster, 2011; Thompson, Baruah, \& Carr, 2011). Both CDM and REDD+ have been identified as sites of political negotiation and contestation, wherein politically charged concepts such as environmental integrity and equity become turned into technical matters, referred to as 'governing by expertise' (Dooley \& Gupta, 2017). The role of governance, notably in the 
CDM, has been linked to the political-economic context in which projects are operating; this in turn heavily influences the quality of the outcomes generated, particularly in developing countries, where there is a need to broaden the capacity of projects to improve their effectiveness (Newell, 2009). Governance has been the focus of several hundred academic papers on REDD+ (Cadman, Maraseni, Breakey, López-Casero, \& Ma, 2016), particularly regarding the vexed issue of how to share the benefits derived from reducing emissions (Chapman, Maguire, Doshi, Kago, Aquino, Kiguatha, Dooley, \& Engbring, 2015; Chapman et al., 2014; Chapman, Wilder, Millar, Dibley, Yeang, Heffernan, Sherchan, Maguire, Kago, Kamunde-Aquino, Kiguatha, Yvonne Nana Afua, Doshi, Engbring, \& Dooley, 2015; Harada, Prabowo, Aliadi, Ichihara, \& Ma, 2015; McGregor, Weaver, Challies, Howson, Astuti, \& Haalboom, 2014). According to commentators and scholars, the so-called 'North South divide' between developed and developing countries has been exacerbated in international climate governance due to arguments around the use of forest carbon under CDM and REDD+ (Abreu Mejía, 2010; Allan \& Dauvergne, 2013; Bäckstrand \& Lövbrand, 2007; Roberts \& Parks, 2006). Given the significant scale of finance for REDD 'readiness', and the potential for results-based payments to generate similar levels of funding, it may be better to call this a 'South North divide', as significant resources are flowing from developed to developing countries, with concomitant impact on perceptions of both REDD+ and CDM (Cadman, 2013).

The investigation below evaluates $\mathrm{CDM}$ and REDD+ against a comprehensive set of governance values, but concentrates largely on the nature of interest representation, and the related concepts of access (understood in terms of the inclusiveness of governance structures), and allocation (understood in terms of the provision of resources, capacity building and benefit sharing). It looks at the views of a range of participants, but focuses especially on evaluating these perceptions from developed and developing country perspectives.

\section{Key developments and policies: overview}

Background: UNFCCC and its institutional arrangements for climate governance 
The United Nations Framework Convention on Climate Change (UNFCCC) entered into force in 1994 and with the aim of preventing 'dangerous anthropogenic interference with the climate system' (Article 2), and is one of the most concrete outcomes of the 1992 UN Conference on Environment and Development (UNCED). The Convention was initially operationalized via the 1997 Kyoto Protocol (KP) in a time when the market- and political ideology of neo-liberalism was in its ascendency. The Kyoto Protocol's market emphasis was demonstrated by its three main policy instruments (or 'flexible mechanisms') aimed at mitigating emissions of greenhouse gases (GHG) via the Clean Development Mechanism $(\mathrm{CDM})$, allowing developed countries to 'offset' their emissions via projects in developing countries, Joint Implementation (JI), a similar model aimed at economies in transition to a market economy, and International Emissions Trading (IET), which was an attempt to link all these activities within an international carbon offsetting economy. The European Union was the first collective polity to enter into the system in 2005 through its own Emissions Trading Scheme (EU ETS), which from 2008 permitted the purchase of 'carbon credits' (referred to as certified emissions reductions, or CERs) from projects established under the CDM, as well as JI projects (Cadman, 2013; Cadman, Eastwood, Michaelis, Maraseni, Pittock, \& Sarker, 2015).

The significance of the Kyoto Protocol was that it stipulated a target that was legally binding for the reduction of greenhouse gases (most notably carbon dioxide) of a minimum of 5.2 percent over the timeframe of 2008-2012, using 1990 as a reference level. The CDM is the only one of the three mechanisms that can be said to be genuinely global in its institutional expression (Maraseni \& Cadman, 2015). This is because it transfers both technology as well as direct project finance from developing countries (referred to as 'Annex I') to developing (or 'Non-annex') countries. The underlying principles were that developed countries could enable sustainable development (an objective of UNCED) by facilitating the exchange (offsetting) of emissions from private sector industry via projects in developing countries (thereby meeting their own national greenhouse gas reduction targets), and removing atmospheric pollution that would not have happened without such initiatives (a Kyoto Protocol requirement referred to as 'additionality'). The first CDM project was registered in 2004 in Brazil, with the number of activities registered growing from 62 to over 7,000 between 2005 and the end of the commitment period, offsetting over one billion tonnes of carbon. Reducing, or avoiding emitting activities (referred to as 'mitigation') was initially the primary focus of activities under the Convention, but this changed over the period 2001- 
2006, between Conference of Parties (COP) 7 (Marrakesh) and COP 12 (Nairobi), as developing countries began to focus on their exposure (or vulnerability) to climate change, and the costs that coping with (referred to as 'adaptation') climate change would entail.

As a result, climate change began to be reframed as not just an environmental issue, but a social one as well, which needed the provision of resources, usually financial, and often somewhat euphemistically referred to as 'capacity building'. While this change in emphasis did not particularly affect how countries began implementing the Kyoto Protocol, it introduced a lack of certainty into the negotiations about what the policy settings would look like after 2012, and the extent to which market mechanisms would continue to be used for mitigation activities. Beyond what might be interpreted as an attempt to merely gain extra funds from developed countries was the inherent problem that the Kyoto Protocol only focused on developed countries' obligations, while several countries - most notably China and India, the largest beneficiaries of CDM projects to the virtual exclusion of all others changed their developmental status over the period, yet remained outside any of the protocol's emissions reductions commitments (Cadman, Eastwood et al. 2015). In other words, the CDM's aim was to serve as a mechanism for aiding sustainable development through financial transfer from high income and high emitting countries to low income and low emitting countries. However, as India and (especially) China moved out of the latter category, the mechanism became increasingly untenable.

This underlying tension came to boil in 2010 at COP 15 (Copenhagen), where there were overly-optimistic expectations for a legally binding new arrangement, but which ultimately failed to deliver anything except a commitment for the Kyoto Protocol to continue in some form, and the vague idea that all countries might reduce emissions through what were referred to as 'intended nationally determined contributions' (INDCs) (Radunsky, 2017). The policy uncertainties generated prior to the expiration of the Kyoto Protocol commitment period resulted in the CDM being declared to be 'imperilled' (CDM-Policy-Dialogue, 2012a, p. (a)2), with further predictions at the time that "if nations permit the CDM mechanism to disintegrate, the political consensus for truly global carbon markets may evaporate" (CDMPolicy-Dialogue, 2012b, p. (b)). Nevertheless, at COP 18 in 2012 the 'Doha' amendment (DA) to the Kyoto Protocol resulted in agreement for a second commitment period from 2013-2020, during which the (by now) 38 signatories would implement emissions reductions of 18 per cent. In terms of total emissions globally, however, it should be stressed that the 
Doha Amendment addresses a mere 15 per cent of emissions, and a number of the original signatories to the protocol did not sign up (Maguire, 2015). With the recognition implicit in Doha Amendment that erstwhile developing countries also had obligations to reduce emissions, new meaning was given to the UN norm of 'common but differentiated responsibilities' (CBDR) between developing and developed countries, and the notion of a 'new market mechanism' began to gain traction, which might redefine the CDM to include developing countries, whilst continuing to serve developed countries' interests. However, there were two hurdles to overcome. The first was in some regions there was an ideological rejection of neo-liberal market mechanisms (especially in Latin America). The second was the growing attraction of financing emissions reductions from improved forest management activities, which had been largely excluded from the CDM, which focussed on planted forests, rather than dealing with deforestation and forest degradation for logging activities in natural forests (Cadman 2015).

This was a deliberate omission on behalf of the CDM, which had been under pressure from NGOs in the early days of the Kyoto Protocol negotiations not to include forests. In 2005, the idea of 'reducing emissions from deforestation' (RED) entered the climate negotiations in the form of an emerging policy discussion. This effectively reinserted forests into the mitigation negotiations, and the proposed mechanism and related programme evolved over time to include 'reducing emissions from deforestation and forest degradation' (REDD), to REDD'plus' at COP 15, to include other non-forestry activities. The idea behind the initiative was to combat forest loss by providing funds to forest actors (largely in the developing and tropical rainforest countries) to reduce their impacts by managing forests more sustainably, either through conservation measures, maintaining or enhancing stocks of carbon, or reducing logging impacts. This would provide funds for developing countries and at the same time allow developed countries to continue offsetting their own emissions through some form of carbon trade, but discussions as to how this might occur have constantly changed over time (de Oliveira, Cadman, Ma, Maraseni, Koli, Jadhav, \& Prabowo, 2013). Rather than delivering tangible results on the ground, payments that have been made to date have been focused largely on assisting developing countries "in building their capacity to benefit from possible future systems of positive incentives for REDD+" (FCPF, 2017).

The initiative, referred to in climate negotiations under the long title of "Reducing emissions from deforestation and forest degradation and the role of conservation, sustainable 
management of forests and enhancement of forest carbon stocks in developing countries", is supported by a range of UN-affiliated entities. A support agency, UN-REDD, provides help to identified countries during the introduction of the programme, referred to as 'REDD+ readiness', through a number of regional and global funds allocated by donor countries. UNREDD operates in collaboration with the UN Development Programme (UNDP), the UN Environment Programme (UNEP), and the Food and Agriculture Organisation (FAO) (UNREDD, 2009). The UN also operates a Multi-Partner Trust Fund Office (MTFO) which allocates and tracks the use of developed country donations, which are distributed through a number of specific programmatic funds, which between 2008 and 2017 totaled more than USD \$3.5 billion. EU countries provided a significant proportion of money, as well as Canada, Japan, and Switzerland. Norway is one of the largest individual donor countries. ${ }^{1}$ The World Bank also plays a role, via its Forest Carbon Partnership Facility (FCPF), and manages two funds - the Readiness Fund, which complements UN-REDD support, and the Carbon Fund, which develops funding arrangements for the future possible purchase and trade of emissions reductions. As an institution, FCPF is made up of country donors, NGOs, and the private sector, and concentrates on the more technical requirements or REDD+, including Readiness Preparation Proposals (RPPs) and Emissions Reduction Programs (ERPs) Pledges and allocated funds have exceeded \$1 billion so far (FCPF, 2017).

A range of further agreements has been negotiated between developed and developing countries under the auspices of the climate negotiations. In 2009 the Copenhagen Accord of COP 15 stipulated that a tranche of funds from the $\$ 100$ billion allocated to climate change management should go to emissions reduction activities in forests (Maraseni \& Cadman, 2015). Donating and accounting for such potentially large funds poses a number of governance challenges for the donor and recipient countries, as recognised in Cancún in 2010, at COP 16. Parties to the Convention agreed to the creation of "guidance and safeguards" to ensure the "transparent and effective national forest governance", including the "full and effective participation of relevant stakeholders, in particular indigenous peoples and local communities", with the usual caveat that this was conditional on "national legislation and sovereignty" (UNFCCC, 2011, p. 26). The negotiations further recognise that "land tenure issues, forest governance issues, [and] gender" need to be taken into consideration (Article 72). Additional efforts to safeguard the needs of stakeholders were

\footnotetext{
${ }^{1}$ See http://mptf.undp.org/tools/search?q=REDD\&qc=project (accessed 08/09/2017).
} 
announced by the REDD+ related agencies themselves in 2011 at COP 17 in Durban, and a number of guidelines were released (FCPF, 2011; UN-REDD, 2012). Together, these governance provisions were further systematized at COP 19, 2013 via the Warsaw Framework for REDD+ (UNFCCC, 2014). The otherwise unstoppable policy momentum of the initiative was briefly checked in Lima 2014 during COP 20, which may be attributed to Parties hedging their bets in anticipation of the outcomes of the forthcoming Paris COP (2015), where the fate of the CDM, and future market mechanisms was expected to be determined (Radunsky, 2017).

The top-down model of the Kyoto Protocol was considerably altered under the Paris Agreement (PA) of 2015, which places much greater emphasis on the role of the private sector, civil society and voluntary approaches. Although nation states continue to have a range of responsibilities around monitoring and reporting of their activities, these requirements fall under the commitments pledged under the framework of each country's nationally determined contributions (NDCs) (Glynn, 2017). The 'bottom-up' philosophy of the Paris Agreement is likely to have major implications for the future of both the CDM and REDD + . Although Article 5 confirms the "existing framework" by which REDD + functions, as well the continuation of "results-based payments" for emissions reduction it also calls for "alternative policy approaches" (UNFCCC, 2015, p. 22). It is possible that this may be an oblique reference to the concept "internationally transferred mitigation outcomes" (ITMOs) of Article 6 (6.2 and 6.3 specifically). Under Article 6.4, the Agreement appears to pave the way for the trading of ITMOs by means of what is referred to as a "mechanism to contribute to the mitigation of greenhouse gas emissions and support sustainable development" (unofficially referred to as the 'sustainable development mechanism'-SDM). But there is no specific reference to the CDM, and its fate remains unclear (UNFCCC, 2015, p. 23).

Decoupling the SDM and REDD+ via two discrete Articles under the Agreement reflects the conflict amongst Parties over whether there should continue to be a role for voluntary market-based approaches to reducing emissions, or whether there should be greater government regulation and by means of non-market measures. Although the viability of the international carbon market continues to be elusive, there continue to be Parties who are pushing for one, despite the on-going lack of certainty that the Paris Agreement will provide for one. There is obviously a market linkage underpinning the push for the SDM. However, there is still no agreement as to whether it will complement, or completely replace, the CDM 
(CIFOR, 2017). What is clear is that all Parties continue to support REDD+. The division between Articles 5 and 6 allows the possibility for an international mechanism to allow for forest-based carbon offsets, while not specifically alluding to them. It is likely that future negotiations will focus on whether whatever mechanism emerges will simply focus on REDD+ projects and payments on the basis of their results, or whether there will be a space for other initiatives that will also lead to some form of offsets (GRET, 2016).

While REDD+ has its detractors, particularly amongst environmental NGOs, it seems to have avoided some of the hostility directed to the CDM historically. The CDM had a number of major design faults in its early days, notably the exploitation of the 'potency' of certain gasses by refrigerator factories in China, who switched technologies and were able to sell their resulting hydroflourocarbon savings as offsets for extremely high prices. Of equal concern was the accreditation of a large number of dam construction projects for hydroelectric power, which proceeded largely without the full, prior, and informed consent (FPIC) of local and indigenous communities, and neglected to put in place effective benefit sharing arrangements with affected parties (Cadman et al., 2015, pp. 29-30). Civil society organisations strenuously opposed many of these activities, but it took the CDM until 2014, two years after the official end of the first Kyoto Protocol commitment period, to provide guidance on stakeholder consultation under the mechanism (Cadman et al., 2015, p. 50). It might be possible to conclude that the focus on safeguards in REDD+ reflects a degree of policy learning from the early days of the CDM, and a desire to ensure better stakeholder participation and coordination (Fujisaki, Hyakumura, Scheyvens, \& Cadman, 2016). REDD+ has nevertheless been unable to avoid criticism entirely, as the nation-state sovereignty provisions of its various agreements continue to create tensions with non-state actors concerning unresolved issues around land tenure and indigenous rights. In addition, there is the even greater uncertainty as to whether the programme is even capable of contributing meaningfully to keeping global temperatures within the $1.5-2^{\circ} \mathrm{C}$ target specified under Paris (Chokkalingam \& Vanniarachchy, 2011; McAfee, 2016).

\section{Key Approaches and Method}

While 'governance' itself may be seen as a neutral term concerning the structures and processes used for steering and coordinating stakeholder interactions within institutions, 
'good' governance has been linked to a wide range of moral, ethical and normative values. The 'thicker', or more comprehensive these values, it is argued, the greater the effectiveness of the climate regime as an integrity system, and the more substantial its institutional integrity and overall legitimacy (Breakey, Cadman, \& Sampford, 2017). 'Institutional integrity' in this context refers to the ongoing capability of the institution to reliably live up to its publicly stated ideals and goals - its 'Public Institutional Justification' (Breakey, Cadman, \& Sampford, 2015). By improving the depth and quality of the interaction between institutional actors and stakeholders in the wider environment, the achievement of thick governance values attends to a lynchpin part (the 'context integrity') of an institution's pursuit of integrity (Breakey et al., 2015; Breakey et al., 2017). In developing a comprehensive set of governance values, and understanding their relationship one to another for evaluation purposes, the researchers have synthesized the work of scholars from the fields of international relations, public administration, comparative politics and environmental policy (Cadman, 2011, pp. 5-18). The researchers particularly acknowledge the pioneering work of Lammerts van Bueren and Blom (Lammerts van Bueren and Blom 1997).

In order to understand how the various institutional arrangements for good governance relate one to another, a hierarchically consistent framework of principles, criteria and indicators (PC\&I), drawn from the literature, was used. Consistency allows for the appropriate location of elements within the framework, avoiding overlap or duplication at another level, and enabling a 'top-down' analysis from principles to criteria and thence to indicators. A principle expresses a specific value. Criteria function at the next level down, and categorise aspects of a principle. Like principles, criteria are not measured directly but are used to determine the degree of compliance with the principle. They are connected to indicators that are hierarchically lower, and denote quantitative or qualitative parameters. Indicators (as they relate to the relevant criterion, and larger principle) can then be used for measurement - in this case measures of the quality of governance. Standards are a set of PC\&I that serve as a basis for monitoring and reporting, or as a reference for assessment of conditions 'on the ground' - in this case, how governance is expressed at any institutional level (Lammerts van Bueren and Blom 1997: 5-35). Table 7.1 below sets out the hierarchical relationship between these PC\&I.

Table 7.1: Hierarchical framework for the assessment of governance quality (Cadman 2011: 17) 


\begin{tabular}{|c|c|c|}
\hline Principle (level 1) & Criterion (level 2) & $\begin{array}{l}\text { Indicator (level } \\
\text { 3) }\end{array}$ \\
\hline \multirow[t]{5}{*}{ "Meaningful participation" } & \multirow[t]{3}{*}{ Interest representation } & Inclusiveness \\
\hline & & Equality \\
\hline & & Resources \\
\hline & \multirow[t]{2}{*}{ Organisational responsibility } & Accountability \\
\hline & & Transparency \\
\hline \multirow[t]{6}{*}{ "Productive deliberation" } & \multirow[t]{3}{*}{ Decision making } & Democracy \\
\hline & & Agreement \\
\hline & & $\begin{array}{l}\text { Dispute } \\
\text { settlement }\end{array}$ \\
\hline & \multirow[t]{3}{*}{ Implementation } & $\begin{array}{l}\text { Behavioural } \\
\text { change }\end{array}$ \\
\hline & & Problem solving \\
\hline & & Durability \\
\hline
\end{tabular}

(Cadman, 2009, p. 104) Note: text format denotes hierarchical level (Principle, Criterion, Indicator)

This framework was used as the basis for a series of internet surveys, conducted between 2010 and 2015, of stakeholders participating in REDD+ and CDM. See Table 7.2 below.

Table 7.2 Summary of survey questions

\begin{tabular}{|l|l|}
\hline Question & $\begin{array}{l}\text { Relevant } \\
\text { Indicator }\end{array}$ \\
\hline Do you think [element] is inclusive of your interests? & Inclusiveness \\
\hline Do you think [element] treats all interests equally? & Equality \\
\hline $\begin{array}{l}\text { What level of resources does [element] provide for you to } \\
\text { participate? }\end{array}$ & Resources \\
\hline $\begin{array}{l}\text { Do you think the various institutional elements in which you } \\
\text { participate are accountable in their dealings with you regarding } \\
\text { the [element] process? }\end{array}$ & Accountability \\
\hline $\begin{array}{l}\text { Do you think the various institutional elements in which you } \\
\text { participate are transparent in their dealings with you regarding } \\
\text { the [element] process? }\end{array}$ & Transparency \\
\hline $\begin{array}{l}\text { Do you consider the [element] processes in which you participate } \\
\text { to act in a democratic manner? }\end{array}$ & Democracy \\
\hline $\begin{array}{l}\text { Do you consider the making of agreements in [element] to be } \\
\text { effective? }\end{array}$ & Agreement \\
\hline Do you consider the settling of disputes in [element] to be & Dispute \\
\hline
\end{tabular}




\begin{tabular}{|l|l|}
\hline effective? & settlement \\
\hline $\begin{array}{l}\text { Do you think [element] will contribute to changing the behaviour } \\
\text { that leads to deforestation and forest degradation in developing } \\
\text { countries? }\end{array}$ & $\begin{array}{l}\text { Behavioural } \\
\text { change }\end{array}$ \\
\hline $\begin{array}{l}\text { Do you think [element] will help solve the problem of } \\
\text { deforestation and forest degradation in developing countries? }\end{array}$ & Problem solving \\
\hline Do you consider [element] will be durable? & Durability \\
\hline
\end{tabular}

(Cadman \& Maraseni, 2013, p. 218; Cadman, Maraseni, Ma, \& Lopez-Casero, 2017, p. 11). Note: Introductory materials and explanatory text not included

Survey participants were recruited through internet-searches of publicly available participants' lists relevant to UNFCCC, REDD+ and CDM. The ensuing email addresses were entered into a database, and the online survey tool SurveyMonkey (http://www.surveymonkey.net) was used to manage the survey. Survey participants were asked to rate the governance quality of REDD+, and the CDM. Survey respondents rated their perceptions of the governance quality by means of a five-point Likert scale, using the terms 'very low', 'low', 'medium', 'high' and 'very high'. Participants were sent a survey, and provided the option of clicking on a link, which took them to the survey, or they could select an option to remove themselves from the list. In addition to the Likert-scale, respondents were invited to make substantive comments relevant to each indicator, and asked if they wished to be interviewed. The surveys were deployed for one month, with three (weekly) reminder emails, and a final forty-eight-hour closure notice. The surveys were anonymous, with confidentiality assured, but with the option for the lead researcher to identify individual respondents.

The survey cohorts (and respondents) were comprised largely of members of the respective policy communities. Respondents were asked to identify as 'Environmental', 'Social', 'Economic', 'Government', 'Secretariat or other institutional component', and 'Other' (who were then asked to specify further). Typically, these were government officials, representatives of intergovernmental and non-governmental organisations (environmental, social and economic), members of the elements under investigation (secretariats or other institutional components), and a few 'others', notably academics and researchers, and individuals who chose to represent themselves more specifically as 'other' (e.g. 'private sector' or 'indigenous peoples' organisation'). Respondents were also invited to identify whether they came from the 'Global North' or 'Developed country', and 'Global South' or 'Developing Country'. 'Environment' and 'government' were generally the highest 
participating groups, followed by 'other', and with a smattering of 'secretariat', followed by 'social' and 'economic'. Generally speaking, North and South were relatively equally represented, with small numbers fluctuating either way in each of the surveys.

Two initial surveys were deployed in 2010 for REDD+ (March) and the CDM (November), which were sent to approximately 800 email addresses for each mechanism. These links proved difficult for tracking respondents (especially if individuals forwarded the link). Subsequently a unique link for each individual respondent was used, generated by the online survey tool, and sent via email. The response rates from these surveys were very low, between three and four percent, although it should be noted that online surveys have generally lower participation rates than other forms of survey technique (Van Selm \& Jankowski, 2006). Further addresses were added to the original survey cohorts to increase the number of responses, approximately 1,000 REDD+ and 1,300 for CDM (accounting for defunct emails and opting out). In the 2010 surveys, completion rates were lower than in 2012 (45 out of 72 for CDM or 63\%; and 44 out of 164 for REDD+ or 27 per cent). Subsequent to implementation of individual emails in 2012, completion rates were much higher at around ninety-five percent, although the overall number of respondents was lower (32 for CDM and 36 for REDD+). These numbers were not high enough to generate anything other than largely anecdotal results, particularly as the respondents across the two mechanisms were not homogenous, which the authors acknowledge, but the results, discussed below, are nevertheless interesting.

In 2014, recognizing the need to refresh the existing databases of respondents, given the inevitable changes in the policy community over time, and to increase response rates, the researchers collected further emails of participants active in a range of climate and sustainability policy mechanisms, including CDM and REDD+, and combined them into a single cohort of approximately 5,300 potential respondents (accounting for defunct emails and opting out). A further category 'academic' was added to this survey on account of the number of 'other' respondents, who specified this sector from the 2010/2012 surveys when asked to clarify. This survey was deployed in February 2015, generating 107 completed responses out of 108 attempts: 90 of these respondents opted to evaluate CDM and REDD+. In the case of REDD+, 41 identified as 'Global North' (developed countries), 49 'Global South' (developing country); for CDM 38 were from the North, 52 from the South. Again, it should be stressed that the respondents were not identical across mechanisms in the 2015 
survey, but they were from the same initial pool of 107 respondents compared to the 2010/2010 REDD+ and CDM respondents, which were completely different from each other. The combined results of these surveys are included in Table 7.3a) below. The results from the 2015 survey are further presented by region (North/South) in Table 7.4) below. For assessment purposes, each responding sector was equally weighted to avoid numerical bias; this same approach was adopted for evaluation by region.

\section{Key Results}


Table 7.3 REDD+ and CDM quality of governance (2010-2015), all sectors combined (weighted average)

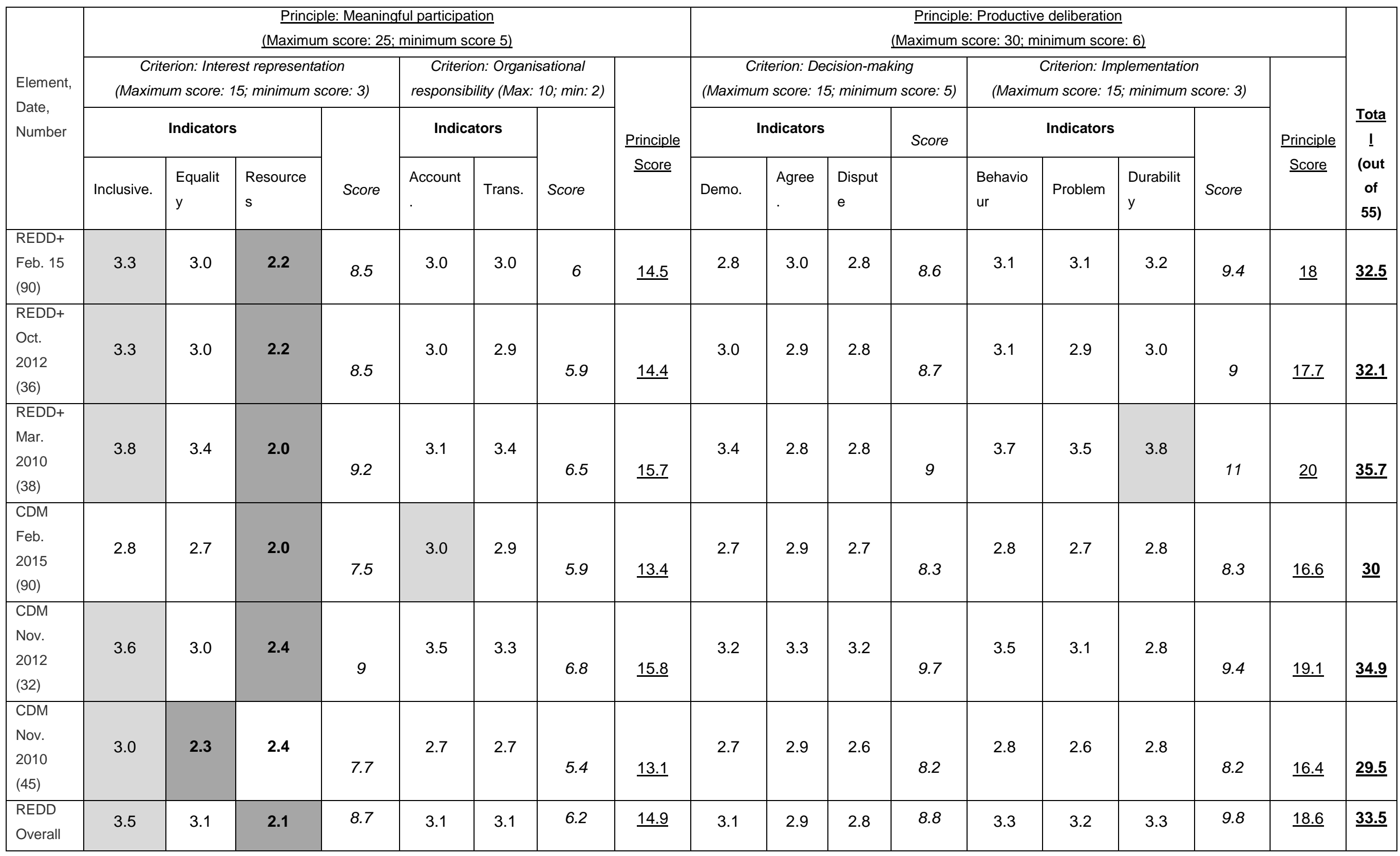




\begin{tabular}{|c|c|c|c|c|c|c|c|c|c|c|c|c|c|c|c|c|c|c|}
\hline Average & & & & & & & & & & & & & & & & & & \\
\hline $\begin{array}{l}\text { CDM } \\
\text { Overall } \\
\text { Average }\end{array}$ & 3.1 & 2.7 & 2.3 & 8.1 & 3.1 & 3.0 & 6.1 & 14.2 & 2.9 & 3.0 & 2.8 & 8.7 & 3.0 & 2.8 & 2.8 & 8.6 & $\underline{17.3}$ & $\underline{31.5}$ \\
\hline
\end{tabular}

Table 7.4 REDD+ and CDM quality of governance (2015), North and South (weighted average)

\begin{tabular}{|c|c|c|c|c|c|c|c|c|c|c|c|c|c|c|c|c|c|c|}
\hline \multirow{2}{*}{$\begin{array}{l}\text { Element, } \\
\text { Date, } \\
\text { Number }\end{array}$} & \multicolumn{3}{|c|}{ Indicators } & \multirow[b]{2}{*}{$\begin{array}{c}\text { Criterion } \\
\text { score }\end{array}$} & \multicolumn{2}{|c|}{ Indicators } & \multirow[b]{2}{*}{$\begin{array}{c}\text { Criterion } \\
\text { score }\end{array}$} & \multirow[b]{2}{*}{$\frac{\text { Principle }}{\text { Score }}$} & \multicolumn{3}{|c|}{ Indicators } & \multirow[b]{2}{*}{$\begin{array}{c}\text { Criterion } \\
\text { score }\end{array}$} & \multicolumn{3}{|c|}{ Indicators } & \multirow[b]{2}{*}{$\begin{array}{c}\text { Criterion } \\
\text { score }\end{array}$} & \multirow[b]{2}{*}{$\frac{\frac{\text { Principle }}{\text { Score }}}{\underline{n^{2}}}$} & \multirow{2}{*}{\begin{tabular}{|c} 
Tota \\
$\underline{1}$ \\
(out \\
of \\
55 )
\end{tabular}} \\
\hline & Inclusive. & $\begin{array}{l}\text { Equalit } \\
y\end{array}$ & $\begin{array}{l}\text { Resource } \\
\mathrm{s}\end{array}$ & & Account. & Trans. & & & Demo. & Agree & $\begin{array}{l}\text { Disput } \\
\mathrm{e}\end{array}$ & & $\begin{array}{l}\text { Behavio } \\
\text { ur }\end{array}$ & Problem & $\begin{array}{l}\text { Durabilit } \\
y\end{array}$ & & & \\
\hline $\begin{array}{l}\text { REDD+ } \\
\text { Feb. } \\
2015 \\
\text { North } \\
(41)\end{array}$ & 3.7 & 2.9 & 1.6 & 8.1 & 2.8 & 2.7 & 5.6 & 13.7 & 2.5 & 2.8 & 2.5 & 7.7 & 3.1 & 2.9 & 3.1 & 9.1 & 16.9 & $\underline{30.5}$ \\
\hline $\begin{array}{l}\text { REDD+ } \\
\text { Feb. } \\
2015 \\
\text { South } \\
(49) \\
\end{array}$ & 3.1 & 3.1 & 2.8 & 9.0 & 3.4 & 3.2 & 6.6 & 15.6 & 3.1 & 3.2 & 3.0 & 9.3 & 3.1 & 3.2 & 3.2 & 9.5 & 18.8 & $\underline{34.4}$ \\
\hline $\begin{array}{l}\text { CDM } \\
\text { Feb. } \\
2015 \\
\text { North } \\
(38)\end{array}$ & 3.0 & 2.7 & 1.6 & 7.3 & 2.7 & 2.7 & 5.3 & 12.6 & 2.4 & 2.8 & 2.3 & 7.4 & 2.7 & 2.4 & 2.6 & 7.8 & 15.2 & $\underline{27.8}$ \\
\hline $\begin{array}{l}\text { CDM } \\
\text { Feb. } \\
2015 \\
\text { South } \\
\text { (52) }\end{array}$ & 2.7 & 2.7 & 2.4 & 7.8 & 3.2 & 3.1 & 6.3 & 14.1 & 2.9 & 3.0 & 3.0 & 8.9 & 2.8 & 2.9 & 2.9 & 8.6 & 17.4 & $\underline{31.5}$ \\
\hline
\end{tabular}

(Cadman et al., 2015; Maraseni \& Cadman, 2015)

Notes: 1) Light grey represents the highest-scoring indicators; 2) Medium-grey the lowest scoring indicators; 3) Numbers in bold are a 'fail' at the indicator

level 
In the 2015 survey, REDD+ received a high 'pass'. Inclusiveness was the highest rated indicator, and resources the lowest (a 'fail'). The results from the 2012 survey - despite being from a largely different cohort of respondents - are remarkably similar to 2015: a slightly weaker 'pass', again with inclusiveness the highest rated indicator and resources the lowest (both exactly the same scores as the 2015 survey). The 2010 survey generated the most positive results: a low 'credit' (sixty five percent); the highest rating indicator was again inclusiveness but this time, shared with durability (3.8 - the highest two ratings across all surveys). The lowest indicator was once again resources (another 'fail'). In the 2015 survey, CDM received a low 'pass'. This time accountability was the highest rated indicator, with resources again the lowest (and a 'fail'). The 2012 survey generated the most positive results for the mechanism, with a high 'pass' (sixty-four per cent). Inclusiveness was the highest rated indicator, resources the lowest (another 'fail'). The 2010 survey was similar to that of 2015: a low 'pass'; with inclusiveness the highest rating indicator; but resources being outranked as the worst indicator by equality (2.3 cf. 2.4 - both 'fails'). Overall, REDD+ clearly performed better than CDM, although interestingly, while REDD+ received the higher rating for inclusiveness (3.5.cf. 3.1), CDM had a slightly better rating for resources $(2.1 c f$. 2.3 - both 'fails' nevertheless).

\section{Commentary - 2015 surveys of REDD + and CDM - North and South}

REDD+ received a relatively high 'pass', but not a 'credit'. The mechanism did pass all principles and criteria across North and Southern respondents however, with Southern respondents providing consistently higher ratings. Resources was again the weakest indicator, with Northern respondents providing a much lower rating than their Southern counterparts (1.6, a 'fail' cf. 2.8). Interestingly, the indicator ratings provided by Northern respondents were more dynamic than those from the South, and included the highest rated indicator (inclusiveness). With the exception of resources, Southern participants rated REDD + governance indicators within the 'high' band, with little differentiation. For the South, accountability was the highest performing indicator. Respondents did not appear to be especially impressed with the CDM however, which received a low 'pass' only. Southern respondents rated the mechanism more favourably - a result that was repeated across both principles. Northern respondents identified interest representation and decision-making as the weakest criteria. At the indicator level, both South and North respondents gave resources 
a low - 'fail' - score, and for Northern respondents, this was the lowest scoring indicator. Democracy and dispute settlement also received a low rating from the North (both 'fails'). The highest performing indicators were inclusiveness (North) and agreement and dispute settlement (South). These higher ratings for agreement and dispute settlement are offset by a 'fail' for dispute settlement among Northern respondents (a 'fail').

\section{Conclusions}

The relative consistency of results for REDD+ and CDM across years and indicators is remarkable, particularly given the different sets of respondents, and response rates. With all scores exceeding thirty, and some exceeding thirty-five, it is a fair observation to say that overall, the perceptions of governance quality of REDD+ amongst respondents were positive. However, there were some inconsistencies in perceptions of governance quality between Northern and Southern respondents in the 2015 survey, with Northern respondents giving a considerably lower score than their Southern counterparts. CDM performed consistently more weakly than REDD+. The highest scoring indicator was generally 'inclusiveness', a positive sign, given the multi-stakeholder nature of climate governance (even if the nation-state remains dominant). Interestingly, there was some recognition given to CDM for its accountability (perhaps reflecting a degree of confidence in its robust accounting methods). However, it is alarming to note that, across years and elements, the lowest scoring indicator was 'resources' the only exception being 'equality' for the 2010 CDM survey (which may reflect the generally poorer perception of CDM amongst respondents in comparison to REDD+).

Given that resources, or capacity, are essential for interest representation, and meaningful participation, attention must be given to addressing this critical area of good governance, as inclusiveness is not in itself sufficient for ensuring good interest representation. Stakeholders require the capacity (financial, educational, technical, institutional, etc.) to ensure that their participation is meaningful, rather than tokenistic. In the planning, implementation and evaluation of mechanisms for combatting climate change, equitable allocation of resources for participation - both in policy development and in implementation - will be one of the principal challenges. This conclusion also informs the recent 'procedural turn' in the literature on climate justice, showing how vital resource-allocations are to secure the ideals laid down by deliberative justice. Participants need not only formal inclusion in deliberations about norms and policies, but the material and technical capabilities to make a genuine contribution. 
Resources are also key in terms of implementation. Without improving livelihoods in a sustainable way, Indigenous and local communities may prefer to convert forests to other land uses, and developing countries may then struggle to meet their NDC targets. However, if the indications of developing country respondents in the 2015 survey are anything to go by, there may be a greater level of support for, and confidence in, the merits of such mechanisms in the Global South, than in the Global North.

It should be further noted that the results were not entirely negative for CDM. Respondents felt that it had relatively good accountability mechanisms in place, although not markedly better than REDD+ (perhaps the latter has learned from CDM with its carbon accounting measures, although this remains to be seen). It is also worth noting that North respondents generally provided lower ratings for everything than South respondents, reflected in both CDM and REDD+. The consistently high ratings for inclusiveness compared to the low ratings for resources would appear to suggest that participants in both REDD+ and CDM felt that they had relatively good access to these mechanisms, but that the allocation of resources to facilitate participation is inadequate. The caveat should be added here that the surveys are capturing people on these forums' participants' lists, so they are by definition included at least to that extent. The value of measuring their perceptions nevertheless is that it allows a comparison between the two. The conclusion suggested is that REDD+ is more inclusive than CDM.

If the SDM is to be successful, it needs to learn from the lessons of both REDD+ and the CDM, and pay greater attention to capacity building amongst under-resourced stakeholders. As these surveys have shown, the application of standards covering a broad suite of governance values, and not just focussing narrowly on accountability and transparency, should be seriously considered by donor countries and private sector investors, if they wish to ensure the integrity of climate governance, and its proper financing. It should give further attention to allocating resources to increase participation, and in sharing future benefits from reducing emissions in the effort to prevent dangerous climate change. Finally, the SDM should give thought to the underlying tensions between developed and developing country participants in climate governance. These could prove damaging in the future if they are not addressed immediately. 


\section{References}

Abreu Mejía, D. (2010). The Evolution of the Climate Change Regime: Beyond a North-South Divide?

Allan, J. I., \& Dauvergne, P. (2013). The global south in environmental negotiations: The politics of coalitions in REDD+. Third World Quarterly, 34(8), 1307-1322.

Bäckstrand, K., \& Lövbrand, E. (2007). Climate governance beyond 2012: competing discourses of green governmentality, ecological modernization and civic environmentalism. The social construction of climate change: Power, knowledge, norms, discourses, 123-147.

Boran, I. (2016). Principles of public reason in the UNFCCC: Rethinking the Equity Framework. Science and Engineering Ethics, 23(5), 1253-1271. doi:10.1007/s11948-016-9779-9

Boran, I., \& Katz, C. (2017). Climate Change Justice. In Routledge Encyclopedia of Philosophy: Taylor and Francis. Retrieved from https://www-rep-routledgecom.libraryproxy.griffith.edu.au/articles/thematic/climate-change-justice/v-1.

Breakey, H. (2015). COP20's Ethical Fallout: The Perils of Principles Without Dialogue. Ethics, Policy \& Environment, 18(2), 156-169.

Breakey, H., Cadman, T., \& Sampford, C. (2015). Conceptualizing Personal and Institutional Integrity: The Comprehensive Integrity Framework. Research in Ethical Issues in Organizations, 14, 1-40. doi:https://doi.org/10.1108/S1529-209620150000014001

Breakey, H., Cadman, T., \& Sampford, C. (2017). Governance values and institutional integrity. In T. Cadman, Maguire, Rowena, Sampford, Charles (Ed.), Governing the Climate Change Regime: Institutional Integrity and Integrity Systems (pp. 16-44). Abingdon: Routledge.

Cadman, T. (2009). Quality, legitimacy and global governance: A comparative analysis of four forest institutions. University of Tasmania,

Cadman, T. (2011). Quality and legitimacy of global governance: case lessons from forestry. New York; Basingstoke: Palgrave Macmillan.

Cadman, T. (2013). Introduction: Global Governance and Climate Change. In Climate Change and Global Policy Regimes (pp. 1-16): Springer.

Cadman, T., Eastwood, L., Michaelis, F. L.-C., Maraseni, T. N., Pittock, J., \& Sarker, T. (2015). The Political economy of sustainable development: policy instruments and market mechanisms: Edward Elgar Publishing.

Cadman, T., \& Maraseni, T. (2013). More equal than others? A comparative analysis of state and nonstate perceptions of interest representation and decision-making in REDD+ negotiations.

Innovation. doi:10.1080/13511610.2013.771880

Cadman, T., Maraseni, T., Breakey, H., López-Casero, F., \& Ma, H. O. (2016). Governance Values in the Climate Change Regime: Stakeholder Perceptions of REDD+ Legitimacy at the National Level. Forests, 7(10), 212.

Cadman, T., Maraseni, T., Ma, H. O., \& Lopez-Casero, F. (2017). Five years of REDD+ governance: The use of market mechanisms as a response to anthropogenic climate change. Forest Policy and Economics, 79, 8-16. doi:10.1016/j.forpol.2016.03.008 
CDM-Policy-Dialogue. (2012a). Climate change, carbon markets and the CDM: A call to action. Retrieved from Luxembourg: http://www.cdmpolicydialogue.org/report/rpt110912.pdf.

CDM-Policy-Dialogue. (2012b). High-Level Panel on the CDM Policy Dialogue. Retrieved from http://cdmpolicydialogue.org

Chapman, S., Maguire, R., Doshi, M., Kago, C. W., Aquino, N. K., Kiguatha, L., . . Engbring, G. (2015). The Elements of Benefit-sharing for REDD+ in Kenya: A Legal Perspective. Carbon \& Climate Law Review : CCLR, 9(4), 283.

Chapman, S., Wilder, M., \& Millar, I. (2014). Defining the Legal Elements of Benefit Sharing in the Context of REDD. Carbon \& Climate Law Review : CCLR, 8(4), 270-281.

Chapman, S., Wilder, M., Millar, I., Dibley, A., Yeang, D., Heffernan, J., . . Dooley, E. (2015). A Legal Perspective of Carbon Rights and Benefit Sharing under REDD+: A Conceptual Framework and Examples from Cambodia and Kenya. Carbon \& Climate Law Review : CCLR, 9(2), 143.

Chokkalingam, U., \& Vanniarachchy, A. (2011). Sri Lanka's REDD+ Potential, Myth Or Reality? : Forest Carbon Asia Colombo.

CIFOR. (2017). Analysis: Getting down to business in Bonn. Retrieved from https://forestsnews.cifor.org/49709/getting-down-to-business-in-bonn?fnl=en

de Oliveira, J. P., Cadman, T., Ma, H. O., Maraseni, T., Koli, A., Jadhav, Y. D., \& Prabowo, D. (2013). Governing the forests: an institutional analysis of REDD+ and community forest management in Asia: International Tropical Timber Organization (ITTO)/United Nations University Institute of Advanced Studies (UNU-IAS), Yokohama, Japan.

Dooley, K., \& Gupta, A. (2017). Governing by expertise: the contested politics of (accounting for) land-based mitigation in a new climate agreement. International Environmental Agreements: Politics, Law and Economics, 17(4), 483-500.

FCPF. (2011). Forest Carbon Partnership Facility Common Approach to Environmental and

Social Safeguards for Multiple Delivery Partners.

FCPF. (2017). About FCPF. Retrieved from https://www.forestcarbonpartnership.org/about-fcpf-0

Forsyth, T. (2009). Multilevel, multiactor governance in REDD+: participation, integration and coordination. In A. Angelsen (Ed.), Realising REDD+: National Strategy and Policy Options (pp. 113-122). Bogor, Indonesia: Center for International Forestry Research (CIFOR).

Fujisaki, T., Hyakumura, K., Scheyvens, H., \& Cadman, T. (2016). Does REDD+ Ensure Sectoral Coordination and Stakeholder Participation? A Comparative Analysis of REDD+ National Governance Structures in Countries of Asia-Pacific Region. Forests, 7(9), 195.

Glynn, P. J., Cadman, T., Maraseni, T. N. (2017). Business, Organized Labour and Climate Policy: Forging a Role at the Negotiating Table. Cheltenham: Edward Elgar Publishing.

GRET. (2016). What role do carbon markets play in the Paris Agreement? . Retrieved from http://www.gret.org/discover-gret/about-us/?lang=en

Harada, K., Prabowo, D., Aliadi, A., Ichihara, J., \& Ma, H.-O. (2015). How Can Social Safeguards of REDD+ Function Effectively Conserve Forests and Improve Local Livelihoods? A Case from 
Meru Betiri National Park, East Java, Indonesia. Land, 4(1), 119-139.

doi:10.3390/land4010119

Hoffmann, M. J. (2011). Climate governance at the crossroads: experimenting with a global response after Kyoto: Oxford University Press.

Janicke, M. (1992). Conditions for environmental policy success: An international comparison. The Environmentalist, 12, 47-58. doi:DOI:10.1007/BF01267594

Jänicke, M. (Ed.) (1996). Democracy as a condition for environmental policy success: The importance of non-institutional factors. Cheltenham and Lyme: Edward Elgar.

Knieling, J., \& Leal Filho, W. (2012). Climate change governance: Springer Science \& Business Media.

Koenig-Archibugi, M. (2006). Introduction: Institutional diversity in global governance. In M. Koenig-Archibugi \& M. Zurn (Eds.), New Modes of Governance in the Global System: Exploring Publicness, Delegation and Inclusiveness (pp. 1-30). Basingstoke, London: Palgrave Macmillan.

Lederer, M. (2011). From CDM to REDD+ - What do we know for setting up effective and legitimate carbon governance? Ecological Economics, 70(11), 1900-1907. doi:10.1016/j.ecolecon.2011.02.003

Lyster, R. (2011). REDD+, transparency, participation and resource rights: the role of law. Environmental science \& policy, 14(2), 118-126.

Maguire, R. (2015). Mapping the integrity of differential obligations within the United Nations framework convention on climate change. In V. P. a. R. M. Hugh Breakey (Ed.), Ethical Values and the Integrity of the Climate Change Regime (pp. 31-42). Farnham: Ashgate

Maraseni, T. N., \& Cadman, T. (2015). A comparative analysis of global stakeholders' perceptions of the governance quality of the clean development mechanism (CDM) and reducing emissions from deforestation and forest degradation (REDD+). International Journal of Environmental Studies, 72(2), 288-304. doi:10.1080/00207233.2014.993569

Mason, M. (1999). Environmental democracy. New York: St Martin's Press.

McAfee, K. (2016). Green economy and carbon markets for conservation and development: a critical view. International Environmental Agreements: Politics, Law and Economics, 16(3), 333353.

McGregor, A., Weaver, S., Challies, E., Howson, P., Astuti, R., \& Haalboom, B. (2014). Practical critique: Bridging the gap between critical and practice-oriented REDD+ research communities. Asia Pacific Viewpoint, 55(3), 277-291. doi:10.1111/apv.12064

Newell, P. (2009). Varieties of CDM governance: some reflections. The Journal of Environment \& Development, 18(4), 425-435.

Radunsky, K., Cadman, Timothy. (2017). Afterword: The long road to Paris: Insider and outsider perspectives. In R. M. a. C. S. Timothy Cadman (Ed.), Governing the climate change regime: Instituional integrity and integrity systems (pp. 250-265). Abingdon: Routledge.

Rhodes, R. A. W. (1997). Understanding governance: Policy networks, governance, reflexivity and accountability. Buckingham: Open University Press. 
Roberts, J. T., \& Parks, B. (2006). A climate of injustice: Global inequality, north-south politics, and climate policy: MIT press.

Schmidt, V. A. (2013). Democracy and Legitimacy in the European Union Revisited: Input, Output and 'Throughput'. Political Studies, 61, 2-22.

Scholte, J. A. (2004). Civil society and democratically accountable global governance. Government and Opposition, 39(2), 211-233. doi:DOI:10.1111/j.1477-7053.2004.00121.x

Smismans, S. (2004). Law, legitimacy, and European governance. Oxford: Oxford University Press.

Stiglitz, J. E. (2003). Globalization and development. In D. Held \& M. Koenig-Archibugi (Eds.), Taming Globalisation: Frontiers of Governance. (pp. 47-67). Cambridge: Polity Press.

Thompson, M. C., Baruah, M., \& Carr, E. R. (2011). Seeing REDD+ as a project of environmental governance. Environmental science \& policy, 14(2), 100-110.

UN-REDD. (2009). Report of the Third Policy Board Meeting Washington D.C., U.S. 29-30 October 2009. Retrieved from http://www.unredd.net/index.php?option=com_docman\&Itemid=134\&view=document\&alias $=1234$-final-report-of-the-3rd-policy-board-english-1234\&category_slug=report-3rd-policyboard-meeting-eng-fr-sp-433

UN-REDD. (2012). UN-REDD Programme Social and Environmental Principles and Criteria.

UNFCCC. (2011). Outcome of the work of the Ad Hoc Working Group on Long-term Cooperative Action under the Convention (Cancun Agreements). Retrieved from

UNFCCC. (2014). Warsaw Framework for REDD-plus. Retrieved from http://unfccc.int/land_use_and_climate_change/redd/items/8180.php

UNFCCC. (2015). Paris Agreement as contained in the report of the Conference of the Parties on its twenty-first session. Retrieved from http://unfccc.int/files/home/application/pdf/paris agreement.pdf

Van Selm, M., \& Jankowski, N. W. (2006). Conducting online surveys. Quality \& Quantity, 40(3), 435-456.

Young, I. M. (2000). Inclusion and democracy. Oxford: Oxford University Press. 